\title{
ANALYSIS OF METHODS OF EFFECTIVE SELECTION OF INVESTMENT PROJECTS FOR METALLURGICAL ENTERPRISES
}

\author{
Natalya A. Podgornaya \\ Donbass State Technical University, Alchevsk, Luhansk People's Republic \\ Larisa A. Motchenko \\ Donbass State Technical University, Alchevsk, Luhansk People's Republic \\ Viktoriya N. Chumachenko \\ Donbass State Technical University, Alchevsk, Luhansk People’s Republic
}

\begin{abstract}
This paper deals with the issues of efficient selection of investment projects of industrial enterprises. We have conducted an analysis of the features of the investment activity at the metallurgical enterprises and identified the major problems preventing effective investment, namely the inertness of attachments and large volumes of financing for investment projects which result in the need to involve multiple sources of investment resources for the implementation of one project.

The social significance of investing in metallurgical industries and dependency of such important industries as construction, defense-industrial and fuel-energy complexes, on metallurgy and the State's interest in modernizing production in its own territory determine the relevance of the chosen topic.

The paper reveals a low level of attractiveness of the metallurgical enterprises for investors and explains the necessity for applying economic and mathematical modeling for optimization of investment projects with different volumes of funding. Within the framework of resolving these problems, the paper reveals and partly solves the challenge of effective selection of investment projects where we propose the use of net present value and benefitcost ratio as selection criteria.

As a result, it has been established that the use of methods of economic-mathematical modelling, in this case the application of the optimization model, usually used to select investment projects with limited resources, in comparison with the method of ranking increases the accuracy of calculations and, therefore, allows obtaining a more efficient $\infty$ solution to the task of investment project selection. A comparative analysis of these methods has been carried out on $\underset{\sim}{ }$ the example of solving the applied problem of selecting investment projects by branch No. 12 of Vneshtorgservis Ltd. Key words: metallurgical enterprises, investment, choice of investment projects, rational choice method, ranking method, efficiency evaluation, optimization model.
\end{abstract}

Citation. Podgornaya N.A., Motchenko L.A., Chumachenko V.N. Analysis of Methods of Effective Selection of Investment Projects for Metallurgical Enterprises. Vestnik Volgogradskogo gosudarstvennogo universiteta. Seriya 3, Ekonomika. Ekologiya [Science Journal of Volgograd State University. Global Economic System], 2018, vol. 20, no. 3, pp. 61-71. (in Russian). DOI: https://doi.org/10.15688/jvolsu3.2018.3.7

\section{АНАЛИЗ МЕТОДОВ ЭФФЕКТИВНОГО ВЫБОРА ИНВЕСТИЦИОННЫХ ПРОЕКТОВ ДЛЯ МЕТАЛЛУРГИЧЕСКОГО ПРЕДПРИЯТИЯ}

\author{
Наталья Александровна Подгорная
}

Донбасский государственный технический университет, г. Алчевск, Луганская Народная Республика 


\section{Лариса Анатольевна Мотченко}

Донбасский государственный технический университет, г. Алчевск, Луганская Народная Республика

\section{Виктория Николаевна Чумаченко}

Донбасский государственный технический университет, г. Алчевск, Луганская Народная Республика

Аннотация. В данной статье рассмотрены вопросы эффективного выбора инвестиционных проектов промышленных предприятий. Проведен анализ особенностей инвестиционной деятельности на металлургических предприятиях и выявлены основные проблемы, препятствующие эффективному инвестированию, а именно: инертность вложений и большие объемы финансирования инвестиционных проектов, которые влекут за собой необходимость привлечения нескольких источников инвестиционных ресурсов для реализации одного проекта.

Социальная значимость инвестирования в предприятия металлургической промышленности и зависимость таких стратегически важных отраслей, как строительство, оборонно-промышленный и топливно-энергетический комплексы, от металлургии, а также заинтересованность государства в модернизации производства на собственной территории, предопределяют актуальность выбранной темы.

В публикации раскрыты проблемы низкой привлекательности металлургических предприятий для инвесторов и обоснована необходимость применения экономико-математического моделирования для оптимизации пула инвестиционных проектов при различных объемах финансирования. В рамках решения этих проблем в работе поставлена и частично решена задача эффективного выбора инвестиционных проектов, где в качестве критериев выбора предложено использовать показатель чистой приведенной стоимости и коэффициент выгоды-затраты.

В результате установлено, что использование методов экономико-математического моделирования, в данном случае - применение оптимизационной модели, обычно используемой для выбора инвестиционных проектов при ограниченности ресурсов, по сравнению с методом ранжирования повышает точность осуществления расчетов и, следовательно, позволяет получить более эффективное решение выбора инвестиционных проектов. Сравнительный анализ указанных методов был проведен на примере решения прикладной задачи выбора инвестиционных проектов, реализуемых предприятием на базе филиала № $123 \mathrm{AO}$ «Внешторгсервис».

Ключевые слова: металлургические предприятия, инвестирование, выбор инвестиционных проектов, метод рационального выбора, метод ранжирования, оценка эффективности, оптимизационная модель.

Цитирование. Подгорная Н. А., Мотченко Л. А., Чумаченко В. Н. Анализ методов эффективного выбора инвестиционных проектов для металлургического предприятия // Вестник Волгоградского государственного университета. Серия 3, Экономика. Экология. - 2018. - Т. 20, № 3. - С. 61-71. - DOI: https://doi.org/ 10.15688/jvolsu3.2018.3.7

\section{Проблема и ее связь с научными и практическими задачами}

Металлургическая промышленность играет существенную роль в мировой экономике, являясь основой строительной отрасли, а также оборонно-промышленного (ОПК) и топливно-энергетического комплексов (ТЭК). Доля металлургии в общем объеме промышленности России близка к $10 \%$, а износ основных фондов стремится к $50 \%$ [12].

На конкурентоспособность предприятий данной отрасли влияет технический уровень основных фондов, что ставит перед металлургической промышленностью задачу модернизации, технического перевооружения и существенного инвестирования в производство.
Анализ сущности и задачи управления инвестициями предприятия отражены в трудах отечественных ученых: В.В. Андреева, В.В. Бочанова, Н.В. Игошина, А.В. Идрисова, Т.Г. Касьяненко, В.П. Красовского, В.М. Лебедева, В.Н. Лившица, В.Д. Миловидова, Н.Л. Маренкова, С.А. Смоляка, М.А. Субботина и др., а также зарубежных ученых: И. Ансоффа, Г. Бирмана, Ю. Бригхэма, Дж. Кейнса, Р. Оуэна, Б. Санто, Б. Твисса, С. Шмидта и др. Инвестиционным процессам в металлургии посвящены работы В.В. Андреева, Л.В. Дорохова, В.Б. Прутковского, В.М. Сафонова, А.Б. Серплина, А.Н. Смирнова, А.Ю. Цупрун.

Экономико-математические модели оптимального выбора рассмотрены в работах И.А. Бланка, В.А. Вербы, П.Л. Виленского, 
В.А. Диленко, В.В. Ковалева, Н.Н. Лепа, Н.Л. Маренкова, В.В. Мыльника.

Несмотря на наличие большого ряда исследований по рассматриваемой теме, не исключается необходимость дальнейшего развития теоретических и методических положений, а также обобщения практического опыта, имеющегося в данной области. Однако анализ работ, опубликованных по теме исследования, свидетельствует, что остаются недостаточно освещенными отдельные аспекты задачи эффективного выбора инвестиционных проектов.

\section{Изложение материала и его результаты}

В мировой практике выделяют формы инвестиций в воспроизводство, такие как: новое строительство, расширение и реконструкция действующего предприятия, техническое перевооружение [6, с. 11].

Рассмотрим проблемы инвестирования в новое строительство и расширение производства. В 2017 г. благодаря росту мирового спроса и снижению китайского экспорта, а также за счет увеличения более чем на $8 \%$ потребления стальной продукции внутри страны, черная металлургия пережила настоящее возрождение. Несмотря на это, по данным сайта Metaltorg.ru мировая загрузка металлургических мощностей к концу 2017 г. составила менее $70 \%$.

При такой загрузке производственных мощностей инвестирование в расширение производства является экономически необоснованным. По мнению финансового директора компании «Северсталь» А. Куличенко, нет смысла инвестировать в производственные мощности из-за чрезмерного производства стали в течение последующих нескольких лет как в глобальном масштабе, так и в России.

Однако данное утверждение не касается производств с высокой добавочной стоимостью. Магнитогорский металлургический комбинат инвестирует в Лысьвенский металлургический завод и планирует нарастить на нем в 2018 г. производство оцинкованной стали с полимерным покрытием в 2 раза. Из этого следует, что инвестирование в высокотехнологичное производство с высокой добавленной стоимостью оправдано.
Рассмотрим проблемы реконструкции и технического перевооружения предприятий. Отрасль металлургии требовала модернизации еще в 90-е годы. Но она не была проведена в связи с распадом Советского Союза и тяжелым этапом становления молодых государств. В настоящее время текущая модернизация предприятий происходит, потому что это неизбежный процесс, ведущий к сокращению производственных затрат, ослаблению нагрузки на окружающую среду, улучшению качества и освоению новых видов продукции.

Целая эпоха в металлургии закончилась с выводом из производства в марте 2018 г. последней, крупнейшей в России мартеновской печи на Выксунском металлургическом заводе. На данном этапе предприятие находится в процессе реконструкции: идет освоение центра финишной обработки труб, в конце года запускается цех по производству насосно-компрессорных труб, в планах - строительство производства бесшовных труб. Инвестиции в производство должны превысить 1 млрд долл.

В процессе модернизации Западно-Сибирского металлургического комбината (ЗСМК) предполагается осуществить перевооружение слябовой машины непрерывного литья заготовок, оптимизировать работу электросталеплавильного цеха, провести реконструкцию углеподготовительного цеха коксохимического производства и реконструировать разливочные мощности в доменном цехе. На осуществление задуманного в 20172018 гг. ЗСМК инвестирует в предприятие 5 млрд рублей.

Новолипецкий металлургический комбинат в 2017 г. инвестировал в модернизацию производства 559 млн долл.

Обращают на себя внимание большие объемы финансирования инвестиционных проектов металлургических предприятий, влекущие за собой сложность в реализации. В связи с тем, что собственных средств, полученных за счет прибыли, и амортизационных отчислений для таких крупных проектов не достаточно, возникает необходимость в привлечении нескольких источников инвестиционных ресурсов для реализации одного инвестиционного проекта. В качестве источников могут выступать: заемное инвестирование (займы, 
поступающие от отечественных, иностранных, международных банков и других организаций, а также выпуск долговых ценных бумаг); акционерное инвестирование (вклады учредителей и стратегических инвесторов); централизованное инвестирование (средства государственного бюджета) и лизинг (вклад лизингодателей) [1, с. 230; 4].

Металлургия относится к числу зрелых отраслей, имеющих низкий уровень инвестиционной привлекательности, характеризуется большой инертностью (цикл «строительство - производство» зачастую превышает 10 лет), поэтому и не является приоритетным объектом вложения финансовых ресурсов для частных инвесторов $[9$, с. $65 ; 13$, с. 7]. В связи с этим государство должно брать на себя решение задач, которые бизнес решить самостоятельно не может, содействовать инвестиционным процессам, происходящим в металлургической отрасли, и создавать дополнительные возможности для ее участников. Следует отметить огромную социальную значимость инвестирования в металлургические предприятия, так как в большинстве случаев они являются градообразующими, а также зависимость стратегических отраслей промышленности (ТЭК, ОПК, строительство и т. д.) от металлургии, что влечет заинтересованность государства в модернизации производства на собственной территории.

В процессе реконструкции металлургического предприятия обычно реализуется не один, а некая совокупность инвестиционных проектов. Поэтому перед руководством предприятия стоит задача выбора тех проектов (обычно в условиях дефицита инвестиционных ресурсов), которые позволяют получить максимальный экономический эффект и решить производственные, научнотехнические и экологические задачи [8, c. $278-279 ; 11$, с. 224].

Предприятие должно провести оценку экономической целесообразности включения инвестиционного проекта в проектный портфель. Существует ряд методов, позволяющих рассчитать максимально допустимый объем инвестиционных ресурсов и сопоставить выгоду от реализации инвестиционных проектов с затратами, необходимыми для их реализации.
Для получения однозначных результатов сравнения проектов при их анализе рекомендуется в качестве главного критерия отбора использовать один из показателей экономической эффективности $[2 ; 7 ; 10 ; 14]$, а именно - показатель чистой приведенной стоимости $(N P V)[3$, c. 262].

Из всего множества проектов $\Omega$ выбираются те, при которых суммарный показатель $N P V$ стремится к максимуму, а общие затраты не превышают выделенных финансовых ресурсов, то есть удовлетворяют условиям [5, с. 138$]$ :

$$
\begin{gathered}
N P V_{\Sigma}=\sum_{j=1}^{m} N V P_{j} \delta_{j} \rightarrow \max , \\
\sum_{j=1}^{m} I_{j} \delta_{j} \leq \Phi, \\
\delta_{j}=\{0,1\}, j=\overline{1, m},
\end{gathered}
$$

где $N P V_{j}$ - чистая приведенная стоимость проекта $j$; $m$ - общее количество анализируемых проектов; $\delta_{j}-$ двоичная переменная. Отражает вхождение проекта $j$ в перечень реализуемых проектов (проект $j$ включается в число реализуемых, если $\delta_{j}=1$, и не включается - при $\left.\delta_{j}=0\right) ; I_{j}-$ финансовые затраты, необходимые для осуществления проекта $j$; $\Phi$ общий объем финансовых ресурсов, выделенных на реализацию портфеля проектов.

В работах по проектному анализу рекомендуется применять коэффициент выгодызатраты (benefit-cost B/C) для решения задачи выбора портфеля реализуемых инвестиционных проектов в условиях ограниченных финансовых ресурсов [3, с. 97]:

$$
\frac{B}{C_{j}}=\beta_{j} \sum_{t=1}^{n_{j}} 1 /(1+i)^{t},
$$

где $\beta_{j}$ - норма прибыли $j$-го проекта; $n_{j}-$ срок реализации $j$-го проекта; $i-$ коэффициент дисконтирования.

Необходимо упорядочить все проекты в порядке убывания данного показателя, а затем из полученного списка взять те, для которых суммарные инвестиционные затраты не превышают выделенные финансовые ресурсы.

Представленные выше основные подходы к решению задачи выбора проектов сводятся к двум методам: ранжирования и оптимизации. 
Практическая реализация и сравнительный анализ указанных методов на примере решения прикладной задачи выбора инновационных проектов, реализуемых предприятием, осуществлялись на базе филиала № 12 ЗАО «Внешторгсервис».

Основные экономические характеристики рассматриваемых инвестиционных проектов филиала № 12 ЗАО «Внешторгсервис» представлены в таблице 1 .

Произведем расчет показателей $\mathrm{B} / \mathrm{C}$ (4) и $N P V$, который для проекта $j$ рассчитывается по формуле (5) [5, с. 142]:

$$
N P V_{j}=\beta_{j} I_{j} \sum_{t=1}^{n_{j}} 1 /(1+i)^{t}-I_{j},
$$

где $I_{j}$ - объем инвестиций, необходимый для реализации проекта $j$.

Значение коэффициента дисконтирования $i$ в расчетах принималось равным 0,1 . Результаты вычислений для каждого из анализируемых проектов сведены в таблицу 2.

В таблицу 3 сведем величины объема необходимых инвестиций $I_{j}$ и объема необходимых инвестиций накопительным итогом $\sum_{j=1}^{m} I_{j} \delta_{j}$, а также критерии экономической эф- фективности реализации выбранных проектов - величину $N P V_{j}$ и величину $N P V$ накопительным итогом $N P V_{\Sigma}$. Упорядочим проекты по убыванию коэффициента выгоды-затраты $\mathrm{B} / \mathrm{C}$, используя метод ранжирования. В результате предложим рациональный вариант решения задачи выбора проектов, основываясь на ранжированном списке таблицы 3 и принимая условие независимости проектов.

Например, если для реализации всех проектов предприятия выделено 50 млн д. ед., то в число реализуемых проектов должны быть включены первые 9 проектов списка таблицы 3 (№ 2, 3, 4, 5, 7, 9, 10, 12, 15), так как общие затраты на их выполнение составляют 48,0405 млн д. ед. Отобранному портфелю проектов соответствует $N P V_{\Sigma}=25719,72$ тыс. д. ед.

Улучшить полученное решение не возможно, так как оно является оптимальным с позиций критерия $N P V_{\Sigma}$.

Однако не всегда использование метода ранжирования позволяет получить наилучшее решение задачи выбора инвестиционных проектов. Рассмотрим ситуацию, когда для осуществления проектов выделено 100 млн д. ед.

Согласно методике ранжирования должны быть выбраны те первые проекты списка, суммарные объемы финансирования которых

Таблица 1

\section{Экономические параметры инвестиционных проектов филиала № 12 ЗАО «Внешторгсервис»}

\begin{tabular}{|c|c|c|c|}
\hline № проекта & $\begin{array}{c}\text { Объем необходимых } \\
\text { инвестиций (тыс. д. ед.) }\end{array}$ & $\begin{array}{c}\text { Средняя норма } \\
\text { прибыли }\end{array}$ & $\begin{array}{c}\text { Срок реализации } \\
\text { проекта (годы) }\end{array}$ \\
\hline 1 & 6416,93 & 0,32 & 4 \\
\hline 2 & 2491,06 & 0,36 & 7 \\
\hline 3 & 4307,81 & 0,32 & 6 \\
\hline 4 & 4606,94 & 0,35 & 6 \\
\hline 5 & 3941,93 & 0,41 & 8 \\
\hline 6 & 25569,70 & 0,20 & 15 \\
\hline 7 & 5173,94 & 0,23 & 7 \\
\hline 8 & 5541,51 & 0,27 & 14 \\
\hline 9 & 2055,89 & 0,22 & 8 \\
\hline 10 & 6834,36 & 0,23 & 13 \\
\hline 11 & 19199,25 & 0,21 & 6 \\
\hline 12 & 12906,53 & 0,20 & 10 \\
\hline 13 & 17000,00 & 0,23 & 12 \\
\hline 14 & 7035,47 & 0,27 & 15 \\
\hline 15 & 5721,50 & 0,23 & 0,19 \\
\hline 16 & 4987,19 & 0,18 & 8 \\
\hline 17 & 27264,77 & & 8 \\
\hline
\end{tabular}

Примечание. Рассчитано авторами по отчетности филиала № 12 ЗАО «Внешторгсервис». 
не превышают заданной величины. В данном случае это проекты № 2, 3, 4, 5, 7, 8, 9, 10, 12 , 15,16 и 17. Общие затраты на финансирование этих проектов составляют 85,83397 млн д. ед., $N P V_{\Sigma}=38$ 698, 27 тыс. д. ед. При этом из вы- деленных 100 млн д. ед. остаются неиспользованными более 14 млн д. ед.

Анализируя таблицу 3 можно увидеть, что полученное решение возможно улучшить, если в число реализуемых проектов добавить не про-

\section{Оценка эффективности инвестиционных проектов на основе показателей $\mathrm{B} / \mathrm{C}$ и $\mathrm{NPV}$}

\begin{tabular}{|c|c|c|}
\hline $\begin{array}{c}\text { № } \\
\text { проекта }\end{array}$ & $\begin{array}{c}\text { Величина } \\
\text { показателя В/C }\end{array}$ & $\begin{array}{c}\text { Величина } \\
\text { показателя } N P V\end{array}$ \\
\hline 1 & 1,03 & 173,49 \\
\hline 2 & 1,74 & 1831,19 \\
\hline 3 & 1,41 & 1770,96 \\
\hline 4 & 1,52 & 2381,50 \\
\hline 5 & 1,54 & 2109,99 \\
\hline 6 & 1,08 & 2053,82 \\
\hline 7 & 1,79 & 4070,17 \\
\hline 8 & 1,30 & 1669,81 \\
\hline 9 & 1,61 & 1256,34 \\
\hline 10 & 1,60 & 4104,28 \\
\hline 11 & 1,12 & 2371,79 \\
\hline 12 & 1,44 & 5658,61 \\
\hline 13 & 1,21 & 3539,41 \\
\hline 14 & 1,16 & 1154,95 \\
\hline 15 & 1,44 & 2536,68 \\
\hline 16 & 1,32 & 1618,75 \\
\hline 17 & 1,36 & 9689,99 \\
\hline
\end{tabular}

Примечание. Рассчитано авторами.

Таблица 2

Ilpu. ченuе. Рассчитано авторами.

Ранжирование проектов по показателю В/C

Таблица 3

\begin{tabular}{|c|c|c|c|c|c|}
\hline $\begin{array}{c}\text { № } \\
\text { проекта }\end{array}$ & $\begin{array}{c}\text { Величина } \\
\text { показателя } \\
\mathrm{B} / \mathrm{C}\end{array}$ & $\begin{array}{c}\text { Объем } \\
\text { необходимых } \\
\text { инвестиций } \\
\text { (тыс. д. ед.) }\end{array}$ & $\begin{array}{c}\text { Объем } \\
\text { необходимых } \\
\text { инвестиций } \\
\text { накопительным } \\
\text { итогом (тыс. д. ед.) }\end{array}$ & $\begin{array}{c}\text { Величина } \\
\text { показателя } N P V\end{array}$ & $\begin{array}{c}\text { Величина } \\
\text { показателя } N P V \\
\text { накопительным } \\
\text { итогом }\end{array}$ \\
\hline 1 & 2 & 3 & 4 & 5 & 6 \\
\hline 7 & 1,79 & 5173,94 & 5173,94 & 4070,17 & 4070,17 \\
\hline 2 & 1,74 & 2491,60 & 7665,54 & 1831,19 & 5901,36 \\
\hline 9 & 1,61 & 2055,89 & 9721,43 & 1256,34 & 7157,70 \\
\hline 10 & 1,60 & 6834,36 & 16555,79 & 4104,28 & 11261,98 \\
\hline 5 & 1,54 & 3941,93 & 20497,72 & 2109,99 & 13371,97 \\
\hline 4 & 1,52 & 4606,94 & 25104,66 & 2381,50 & 15753,47 \\
\hline 15 & 1,44 & 5721,50 & 30826,16 & 2536,68 & 18290,15 \\
\hline 12 & 1,44 & 12906,53 & 43732,69 & 5658,61 & 23948,76 \\
\hline 3 & 1,41 & 4307,81 & 48040,50 & 1770,96 & 25719,72 \\
\hline 17 & 1,36 & 27264,77 & 75305,27 & 9689,99 & 35409,71 \\
\hline 16 & 1,32 & 4987,19 & 80292,46 & 1618,75 & 37028,46 \\
\hline 8 & 1,30 & 5541,51 & 85833,97 & 1669,81 & 38698,27 \\
\hline 13 & 1,21 & 17000,00 & 102833,97 & 3539,41 & 42237,68 \\
\hline 14 & 1,16 & 7035,47 & 109869,44 & 1154,95 & 43392,63 \\
\hline 11 & 1,12 & 19199,25 & 129068,69 & 2371,79 & 45764,42 \\
\hline 6 & 1,08 & 25569,70 & 154638,39 & 2053,82 & 47818,24 \\
\hline 1 & 1,03 & 6416,93 & 161055,32 & 173,49 & 47991,73 \\
\hline
\end{tabular}

Примечание. Рассчитано авторами. 
ект № 13, который непосредственно следует в списке за проектом № 8 (затраты на его реализацию значительно превышают 14 млн д. ед.), а проекты № 14 (объем финансирования 7 035,47 тыс. д. ед.) и проект № 1 (объем финансирования 6 416,93 тыс. д. ед.).

В результате суммарный показатель $N P V$ реализуемых проектов увеличится на величину 1328,44 тыс. д. ед. и составит 40 026,17 тыс. д. ед., а из выделенных 100 млн д. ед. остаются неиспользованными 0,71 млн д. ед.

Возможен и другой вариант улучшения исходного решения. Если из списка реализуемых проектов удалить проект № 8, а внести проект № 13, то показатель $N P V_{\Sigma}$ реализуемых проектов составит 40 567,87 тыс. д. ед. (что выше предыдущего варианта), а из выделенных 100 млн д. ед. остаются неиспользованными 2,71 млн д. ед.

Заметим, что, как следует из таблицы 3 , есть и другие варианты улучшения исходного решения. Таким образом, метод ранжирования инвестиционных проектов по убыванию удельного показателя их экономической эффективности не позволяет получить наилучшее решение задачи выбора инвестиционных проектов в условиях дефицита финансовых ресурсов.

Решим данную задачу методом оптимизации (1)-(3). В качестве значений коэффициентов $N P V_{j}$ целевой функции (1) должны рассматриваться величины показателя $N P V$ проектов, приведенные в столбце 5 таблицы 3 , а коэффициентам $I_{j}$ ограничений (2) отвечают значения необходимых объемов финансирования отдельных проектов, содержащиеся в столбце 3. Параметру Ф можно придавать различные значения.

Результаты решения задачи (1)-(3) при различных объемах финансирования получены в Excel с помощью средства «Поиск решения〉 и представлены в таблице 4. В этой же таблице приведены аналогичные решения, но полученные методом ранжирования. Сравним решения, найденные различными методами.

При $\Phi=100$ млн д. ед. оптимальное решение имеет вид $\delta_{1}=0, \delta_{2}=1, \delta_{3}=1, \delta_{4}=1$, $\delta_{5}=1, \delta_{6}=0, \delta_{7}=1, \delta_{8}=1, \delta_{9}=1, \delta_{10}=1, \delta_{11}=0$, $\delta_{12}=1, \delta_{13}=1, \delta_{14}=0, \delta_{15}=1, \delta_{16}=0, \delta_{17}=1$. Этому решению соответствует оптимальное значениецелевой функции $N P V_{\Sigma}=40618,9$ тыс. д. ед.

Такие значения переменных $\delta_{j}$ означают, что при общем объеме финансирования проектов $\Phi=100$ млн д. ед. максимальное значение суммарной величины их показателей $N P V$ будет получено при реализации инвестиционных проектов предприятия № 2, 3, 4, 5, 7 , $8,910,12,13,15$ и 17.

Сравнивая решения задачи выбора инвестиционных проектов двумя методами, отметим, что при одних объемах финансирования ( $=50,80,90$ и 160 млн д. ед.) списки реализуемых проектов совпадают, а при других - отличаются. Например, при $\Phi=100$ млн д. ед. в списках проектов, полученных методом оптимизации, отсутствует проект № 16, но включен проект № 13. В результате суммарная ве-

Таблийа 4

Решение задачи выбора проектов при различных объемах финансирования

\begin{tabular}{|c|c|c|c|c|}
\hline \multirow{2}{*}{$\begin{array}{c}\text { Объем } \\
\text { финанси- } \\
\text { рования } \\
\text { (млн. д. } \\
\text { ед.) } \\
\end{array}$} & \multicolumn{2}{|c|}{ Реализуемые проекты } & \multicolumn{2}{|c|}{$\begin{array}{c}\text { Величина показателя } \\
\text { суммарного } N P V\end{array}$} \\
\hline & Метод ранжирования & Метод оптимизации & $\begin{array}{c}\text { Метод } \\
\text { ранжирования }\end{array}$ & $\begin{array}{c}\text { Метод } \\
\text { оптимизации }\end{array}$ \\
\hline 30 & $2,4,5,7,9,10$ & $2-5,7,9,10$ & 15753,5 & 17524,4 \\
\hline 50 & $2-5,7,9,10,12,15$ & $2-5,7,9,10,12,15$ & 25719,7 & 25719,7 \\
\hline 60 & $2-5,7,9,10,12,15$ & $2-5,7-10,12,15,16$ & 25719,7 & 29008,3 \\
\hline 70 & $2-5,7,9,10,12,15$ & $2-5,7,9,10,12,17$ & 25719,7 & 32873,0 \\
\hline 80 & $2-5,7,9,10,12,15,17$ & $2-5,7,8,10,12,15,17$ & 35409,7 & 35823,2 \\
\hline 90 & $2-5,7-10,12,15-17$ & $2-5,7-10,12,15-17$ & 38698,3 & 38698,3 \\
\hline 100 & $2-5,7-10,12,15-17$ & $2-5,7-10,12,13,15,17$ & 38698,3 & 40618,9 \\
\hline 120 & $2-5,7-10,12-17$ & $1-5,7-10,12-17$ & 43392,6 & 43566,1 \\
\hline 140 & $2-5,7-17$ & $1-5,7-17$ & 45764,4 & 45937,9 \\
\hline 160 & $2-17$ & $2-17$ & 47818,2 & 47818,2 \\
\hline
\end{tabular}

Примечание. Рассчитано авторами. 
личина экономического показателя $N P V$ выросла с 38 698,3 до 40 618,9 тыс. д. ед., то есть на 1 920,6 тыс. д. ед.

Еще более значительный рост показателя суммарного $N P V$ при сравнении двух методов будет наблюдаться при других значениях общих объемов финансирования.

Например, как видно из таблицы 4, при $\Phi=60$ млн д. ед. и $\Phi=50$ млн д. ед. методом ранжирования выбран одинаковый перечень проектов. Использование оптимизационной модели при $\Phi=60$ млн д. е. позволяет включить в список реализуемых проектов дополнительно проекты № 8 и 16 . Такому решению соответствует значение показателя эффективности $N P V_{\Sigma}=29008,3$ тыс. д. е., что превышает аналогичный показатель, полученный методом ранжирования, на 3 288,6 тыс. д. е.

Таким образом, проведенные расчеты показывают, что более предпочтительным является решение задачи выбора инвестиционных проектов с использованием математической модели (1)-(3). Этот подход сложнее, чем метод ранжирования проектов по некоторым показателям их эффективности, однако он позволяет получить лучшее решение рассматри- ваемой задачи (см. рисунок) и соответственно больший экономический эффект.

Попробуем еще усложнить задачу выбора проектов. Предположим, что инвестировать в проект № 7 будет целесообразно, если осуществляются подготовительные инвестиционные проекты № 1 и № 13 (например, запуск конвертера при увеличении мощности кислородного цеха и постройки воздуховода). Тогда математическая модель вида (1)-(3) будет дополнена следующим ограничением:

$$
\delta_{7}=\delta_{1}=\delta_{13}
$$

При дополнительных ограничениях и объеме финансирования $\Phi=90$ млн д. е. проект № 7 выбывает из списка, несмотря на то, что при использовании метода ранжирования он стоит на первом месте, при этом дополнительно реализуется проект № 14. Такому решению соответствует значение показателя эфôåêòèâi î ñòè $N P V_{\Sigma}=35783,0$ тыс. д. е., что меньше аналогичного показателя, полученного без дополнительных ограничений на 2 915,3 тыс. д. е. (см. табл. 5).

Проект № 7 возможно реализовать, если объем финансирования увеличится до

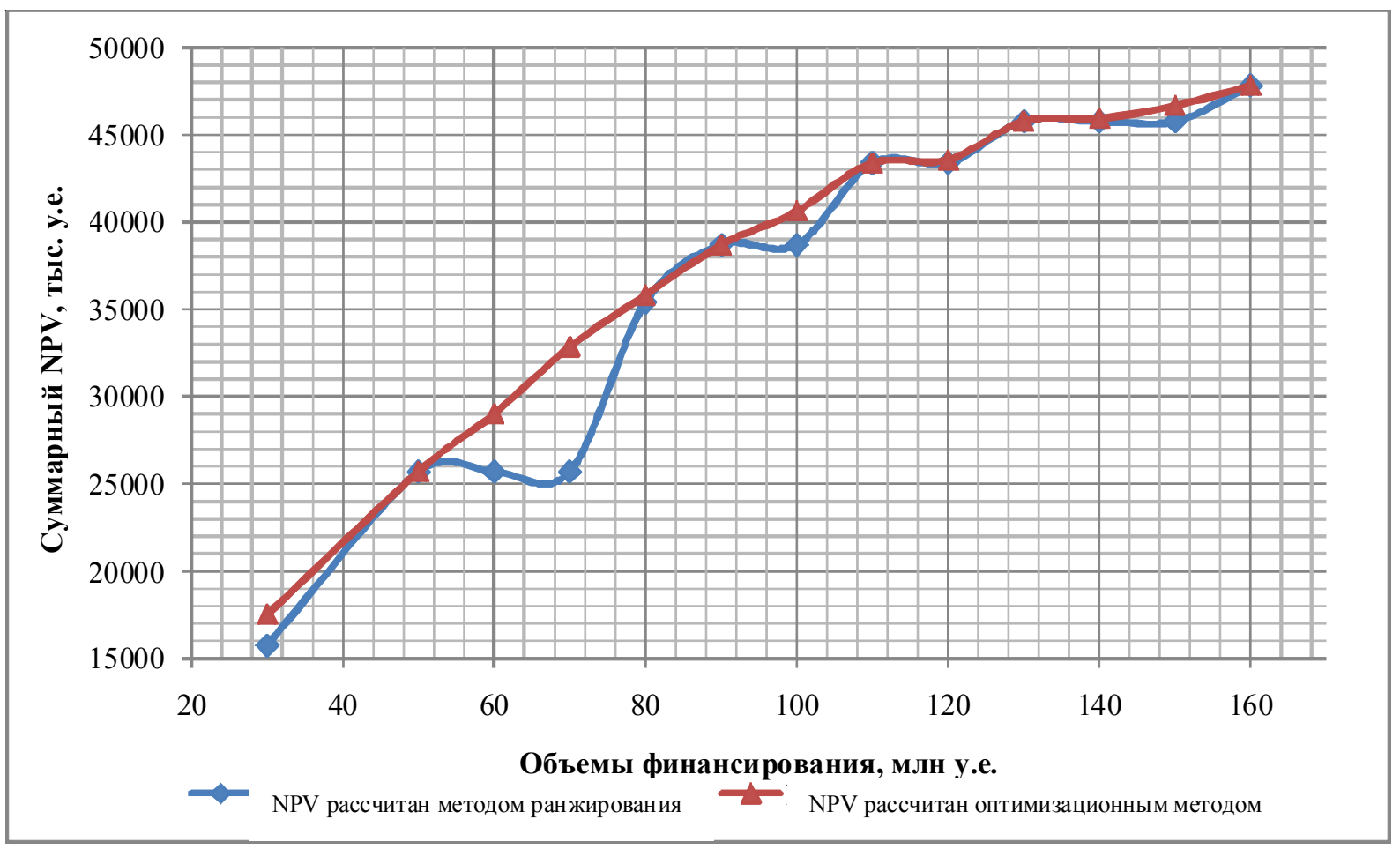

Рисунок. Значения показателя суммарного для решения задачи выбора проектов, полученные различными методами

Примечание. Составлено по расчетам авторов. 


\section{Решение задачи выбора проектов при различных объемах финансирования}

с дополнительными ограничениями

\begin{tabular}{|c|l|l|c|c|}
\hline \multirow{2}{*}{$\begin{array}{c}\text { Объем } \\
\text { финанси- } \\
\text { рования } \\
\text { (млн д. ед.) }\end{array}$} & \multicolumn{2}{|c|}{ Реализуемые проекты } & \multicolumn{2}{|c|}{$\begin{array}{c}\text { Величина показателя } \\
\text { суммарного } N P V\end{array}$} \\
\cline { 2 - 5 } & оптимзации & $\begin{array}{l}\text { Метод оптимизации } \\
\text { с дополнительным } \\
\text { ограничением }\end{array}$ & $\begin{array}{c}\text { Метод } \\
\text { оптимизации }\end{array}$ & $\begin{array}{c}\text { Метод } \\
\text { оптимизации } \\
\text { с дополнительным } \\
\text { ограничением }\end{array}$ \\
\hline 90 & $\begin{array}{l}2-5,7-10,12, \\
15-17\end{array}$ & $\begin{array}{l}2-5,8-10,12,14- \\
17\end{array}$ & 38698,3 & 35783,0 \\
\hline 100 & $\begin{array}{l}2-5,7-10,12, \\
13,15,17\end{array}$ & $\begin{array}{l}1-5,7,9,10,12, \\
13,15,17\end{array}$ & 40618,9 & 39122,6 \\
\hline
\end{tabular}

Примечание. Рассчитано авторами.

$\Phi=100$ млн д. е. По сравнивнению с предыдущей ситуацией финансирования в этом случае появляются соответственно проекты № 1 , 7 и 13, но отклоняются проекты № 8, 14 и 16.

Если провести сравнение с методом оптимизации без дополнительных ограничений при уровне финансирования $\Phi=100$ млн д. ед., то появляется проект № 1 и отклоняется проект № 8. Это приводит к уменьшению значения показателя эффективности на 1 496,3 тыс. д. ед.

Проведенный анализ показал, что использование методов экономико-математического моделирования, в данном случае применение оптимизационной модели, по сравнению с методом ранжирования позволяет получить более эффективное решение выбора инвестиционных проектов. Однако оптимизационная модель, обычно используемая для выбора инвестиционных проектов при ограниченности инвестиционных ресурсов, является в значительной степени идеализированной, не учитывает ряд важных аспектов осуществления реальных проектов. Это требует дальнейшей модернизации модели и внесения дополнительных ограничений.

\section{СПИСОК ЛИТЕРАТУРЫ}

1. Андреев, В. В. Основные направления инвестиционных проектов и особенности их реализации в металлургической промышленности / В. В. Андреев // Вестник МГТУ. - 2010. - Т. 13, № 1. - C. 228-231.

2. Бланк, И. А. Инвестиционный менеджмент : учеб. курс / И. А. Бланк. - Киев : Эльга-Н : Ника-Центр, 2001. - 448 с.
3. Верба, В. А. Проектний аналіз : підручник / В. А. Верба, О. А. Загородніх. - Киев : КНЕУ, 2000. -322 c.

4. Виленский, П. Л. Оценка эффективности инвестиционных проектов. Теория и практика : учеб. пособие / П. Л. Виленский, В. Н. Лившиц, С. А. Смоляк. -4-е изд. - М. : Дело, 2008. -1104 с.

5. Диленко, В. А. Экономико-математическое моделирование инновационных процессов : монография / В. А. Диленко. - 2-е изд., перераб. и доп. Одесса : Феникс, 2013. - 348 с.

6. Инвестиции в черную металлургию России : текущая ситуация // Металлургический бюллетень. -2002 . - № 3. - С. 10-13.

7. Ковалев, В. В. Финансовый анализ: Управление капиталом. Выбор инвестиций. Анализ отчетности / В. В. Ковалев. - 2-е изд., перераб. и доп. М. : Финансы и статистика, 2000. -512 с.

8. Маренков, Н. Л. Основы управления инвестициями / Н. Л. Маренков. - М. : Едиториал УРСС, 2003. $-480 \mathrm{c}$.

9. Металлургические мини-заводы : монография / А. Н. Смирнов, В. М. Сафонов, Л. В. Дорохова, А. Ю. Цупрун. - Донецк : Изд-во ДонНТУ : НордПресс, 2005. -469 c.

10. Модернизация экономики на основе технологических инноваций / А. Н. Асаул, Б. М. Карпов, В. Б. Перевязкин, М. К. Старовойтов. - СПб. : АНО ИПЭВ, 2008. -606 c.

11. Мыльник, В. В. Инвестиционный менеджмент : учеб. пособие для вузов / В. В. Мыльник. 4-е изд. - Екатеринбург : Деловая книга ; М. : Академический Проект, 2005. - 271 с.

12. Объем отгруженных товаров собственного производства, выполненных работ и услуг собственными силами по отдельным видам экономической деятельности Российской Федерации // Сайт Федеральной службы государственной статистики. - Электрон. текстовые дан. - Режим доступа: http://www.gks.ru/ wps/wcm/connect/rosstat_main/ 
rosstat/ru/ statistics/enterprise/industrial/\# (дата обращения: 02.05.2018) - Загл. с экрана.

13. Серплин, А. Б. Оценка уровня инвестиционной привлекательности черной металлургии / А. Б. Серплин, В. Б. Прутковский // Металлург. 1998. -№ 9.- С. 6-9.

14. Яшин, С. Н. Экономика и финансовое обеспечение инновационной деятельности : учебник. В 2 т. Т. 1. Экономика / С. Н. Яшин, И. Л. Туккель, Е. В. Кошелев.-СПб. : БХВ-Петербург, 2014. -688 с.

\section{REFERENCES}

1. Andreev V.V. Osnovnye napravleniya investitsionnykh proektov i osobennosti ikh realizatsii v metallurgicheskoy promyshlennosti [The Main Areas of Investment Projects and Their Implementation in the Metallurgical Industry]. Vestnik MGTU, 2010, vol. 13, no. 1, pp. 228-231.

2. Blank I.A. Investitsionnyy menedzhment [Investment Management]. Kiev, Elga-N; Nika-Tsentr Publ., 2001. 448 p.

3. Verba V.A., Zagorodnikh O.A. Proektnyy analiz [Project Analysis]. Kiev, KNEU Publ., 2000. 322 p.

4. Vilenskiy P.L. Otsenka effektivnosti investitsionnykh proektov. Teoriya $i$ praktika [Evaluating the Effectiveness of Investment Projects. Theory and Practice]. Moscow, Delo Publ., 2008. 1104 p.

5. Dilenko V.A. Ekonomiko-matematicheskoe modelirovanie innovatsionnykh protsessov [Economic and Mathematical Modeling of Innovative Processes]. Odessa, Feniks Publ., 2013. 348 p.

6. Investitsii v chernuyu metallurgiyu Rossii: tekushchaya situatsiya [Investments in Ferrous Metallurgy in Russia: Current Situation]. Metallurgicheskiy byulleten, 2002, no. 3, pp. 10-13.

7. Kovalev V.V. Finansovyy analiz: Upravlenie kapitalom. Vybor investitsiy. Analiz otchetnosti
[Financial Analysis: Capital Management. The Choice of Investment. Analysis of Reporting]. Moscow, Finansy i statistika Publ., 2000. 512 p.

8. Marenkov N.L. Osnovy upravleniya investi-tsiyami [Fundamentals of Investment Management]. Moscow, Editorial URSS Publ., 2003. $480 \mathrm{p}$.

9. Smirnov A.N. Metallurgicheskie mini-zavody [Metallurgical Mini-Plants]. Donetsk, Nord-Press, 2005.469 p.

10. Asaul A.N., Karpov B.M., Perevyazkin V.B., Starovoytov M.K. Modernizatsiya ekonomiki na osnove tekhnologicheskikh innovatsiy [Modernization of the Economy Based on Technological Innovations]. Saint Petersburg, ANO IPEV Publ., 2008. 606 p.

11. Mylnik V.V. Investitsionnyy menedzhment [Investment Management]. Ekaterinburg, Delovaya kniga Publ., Moscow, Akademicheskiy Proekt Publ., 2005. $271 \mathrm{p}$.

12. Obyem otgruzhennykh tovarov sobstvennogo proizvodstva, vypolnennykh rabot i uslug sobstvennymi silami po otdelnym vidam ekonomicheskoy deyatelnosti Rossiyskoy Federatsii [The Volume of Self-Produces Shipped Goods, Performed Works and Services for Certain Types of Economic Activity of the Russian Federation]. URL: http://www.gks.ru/wps/wcm/connect/rosstat_main/ rosstat/ru/statistics/enterprise/industrial/\# (accessed 2 May2018).

13. Serplin A.B., Prutkovskiy V.B. Otsenka urovnya investitsionnoy privlekatelnosti chernoy metallurgii [Assessing the Level of Black Mettalurgy's Investment Attractiveness]. Metallurg, 1998, no. 9, pp. 6-9.

14. Yashin S.N., Tukkel I.L., Koshelev E.V. Ekonomika i finansovoe obespechenie innovatsionnoy deyatelnosti. V 2 t. T. 1. Ekonomika [Economics and Financial Support of Innovation. In 2 vols. Vol. 1. Economics]. Saint Petersburg, BKHV-Peterburg Publ., 2014. $688 \mathrm{p}$.

\section{Information about the Authors}

Natalya A. Podgornaya, Candidate of Sciences (Engineering), Senior Lecturer, Department of Economic Cybernetics and Information Technologies, Donbass State Technical University, Prosp. Lenina, 16, 94204 Alchevsk, Luhansk People's Republic, nataly.podgorna@gmail.com.

Larisa A. Motchenko, Assistant, Department of Economic Cybernetics and Information Technologies, Donbass State Technical University, Prosp. Lenina, 16, 94204 Alchevsk, Luhansk People's Republic, 1.f.motchenko@gmail.com.

Viktoriya N. Chumachenko, Master Student, Department of Economics and Management, Donbass State Technical University, Prosp. Lenina, 16, 94204 Alchevsk, Luhansk People's Republic, v_chumachenko_v@mail.ru. 


\section{Информация об авторах}

Наталья Александровна Подгорная, кандидат технических наук, старший преподаватель кафедры экономической кибернетики и информационных технологий, Донбасский государственный технический университет, просп. Ленина, 16, 94204 г. Алчевск, Луганская Народная Республика, nataly.podgorna@gmail.com.

Лариса Анатольевна Мотченко, ассистент кафедры экономической кибернетики и информационных технологий, Донбасский государственный технический университет, просп. Ленина, 16, 94204 г. Алчевск, Луганская Народная Республика, 1.f.motchenko@gmail.com.

Виктория Николаевна Чумаченко, магистрант группы ЭПМ-13 кафедры экономики и управления, Донбасский государственный технический университет, просп. Ленина, 16, 94204 г. Алчевск, Луганская Народная Республика, v_chumachenko_v@mail.ru. 